\title{
Strong and bulky paperboard sheets from surface modified CTMP, manufactured at low energy
}

Gunilla Pettersson, Hans Höglund, Sven Norgren, Jessica Sjöberg, Frank Peng, Hans Hallgren, Anders Moberg, Carl-Henrik Ljungqvist, Jörgen Bergström and Daniel Solberg

KEYWORDS: CTMP, Starch, CMC, Multilayer, Paperboard, Strength properties

SUMMARY: A description is given regarding methods used to manufacture strong and bulky sheets from furnishes based on a broad range of surface modified CTMP qualities. Starch and CMC are adsorbed on the fibre surfaces using a multilayer or a MIX concept. It is shown that both the in-plane and out-of-plane strength for the CTMP based sheets after such surface treatment can be more than doubled at a maintained density. This can be utilized to improve bending stiffness or to reduce the basis weight in multi-ply paperboards.

\section{ADDRESSES OF THE AUTHORS:}

Gunilla Pettersson (gunilla.pettersson@miun.se), Hans Höglund (hans.hoglund@miun.se), Sven Norgren (sven.norgren@miun.se), Mid Sweden University, SE85170 Sundsvall, Sweden.

Jessica Sjöberg (jessica.sjoberg@sca.com). Jörgen Bergström (jorgen.bergstrom@sca.com). Daniel Solberg (daniel.solberg@sca.com), SCA Östrand Mill, SE-861 81 Timrå, Sweden.

Frank Peng (frank.peng@storaenso.com), Hans Hallgren (hans.hallgren@storaenso.com), Anders Moberg (anders.moberg@storaenso.com), Carl-Henrik Ljungqvist (carl-henric.ljungqvist@storaenso.com), Stora Enso Research Centre, SE-656 37 Karlstad, Sweden.

\section{Corresponding author: Gunilla Pettersson}

The main goal of this study was to find cost-efficient furnishes for a centre ply of a multi-ply paperboard, in which CTMP is added to improve the bending stiffness of the final product. CTMP qualities, which covered a broad range of properties, were evaluated in furnishes with differently beaten kraft pulps. To achieve optimal combinations of high out-of-plane strength and bulk (low density), the surfaces of the CTMP fibres were modified by means of combinations of cationic and anionic polymers (starch and CMC) in order to obtain improved fibre-fibre bond strength.

Presently, most paperboard products are based on multiply technologies (Laamanen, Lahti 2008). In these products, each ply is characterized by specific properties with the purpose of designing high quality composites. Mechanical and chemimechanical pulps are most efficiently used in plies, for which it is worth striving for a high bulk, e.g. in the centre ply in three-ply sheets (Fellers et al. 1983, Fineman 1985, Thomas 1997, Bengtsson 2005). The most important purpose for mechanical or chemimechanical pulps in furnishes that form such a ply is to create a high distance between the outer layers. Such a composite will thus achieve an enhanced bending stiffness as compared to homogenous sheets, when the bulky middle ply is combined with strong top and reverse plies with a high tensile stiffness
(Fellers et al. 1983, Fineman 1985, Tomas 1997, Bengtsson 2005). An obvious prerequisite in relation to achieving a high bending stiffness is that the internal fibre-fibre bond strength is sufficiently high to prevent splits in the porous middle ply during the converting processes. Good formation is also important for other reasons, e.g. to obtain a good appearance and printability. The latter properties can be difficult to achieve with a mechanical pulp which has too high a content of long fibres. On the other hand, high long fibre content improves the tear strength in the sheet, which is advantageous in many product applications (Bengtsson 2005).

Paper sheets from mechanical and chemimechanical pulps have a higher bulk (lower density) than sheets from chemical pulps at equivalent strength properties (Höglund, Wilhelmsson 1992). The highest bulk levels from pulps, which can, simultaneously, be manufactured at very low shive contents, are usually considered to be achieved in CTMP processes from softwoods (Höglund, Wilhelmsson 1992). A prerequisite to be able to form a sheet with a high bulk is that it consists of fibres with a high bending stiffness (Höglund 2002). In CTMP processes, the native fibre bending stiffness from the wood is best preserved, when components in the fibre wall are dissolved or are softened by either thermal or chemical treatments to as low an extent as is possible. Furthermore, the energy consumption in mechanical treatments should be low in order to be able to prevent mechanically induced cracks in the fibre walls and with regards to the peeling off of fine materials from the outer layers of the fibre walls. Further refining, following what is merely required to manufacture a fibre material with sufficiently low shive content, certainly results in improved strength properties but, at the expense of a reduction in bulk.

In the HTCTMP process using softwoods, chips are impregnated with a slightly alkaline solutions of $\mathrm{Na}_{2} \mathrm{SO}_{3}$ (pH 9-10) followed by preheating and refining at a temperature well above the softening temperature of lignin (Höglund, Wilhelmsson 1992, Höglund et al. 1994 Höglund 2002). When the lignin rich middle lamella in the fibre wall are softened in this way, pulps with a combination of very low shive content and high long fibre content can be manufactured at a low electrical energy input in the refining stage. HTCTMP from softwoods can be manufactured with almost the same long fibre content as chemical softwood pulps (Höglund, Wilhelmsson 1992). Recent results from mill experiences have shown that a correspondingly unique combination of high sheet bulk and internal bond strength as that for spruce HTCTMP can also be reached from birch HTCTMP, in spite of its shorter mean fibre length (Westerlind, Höglund 2006). Hardwood chips are impregnated with a $\mathrm{Na}_{2} \mathrm{SO}_{3}$ solution at a higher $\mathrm{pH}$ than 
in the case of softwood, as it is well known that the amount of added alkaline in the impregnation stage has a significant influence on most sheet properties from hardwood CTMP (Jackson et al. 1984, Moldenius, Jackson 1989, Granfeldt et al. 2001). This is in contrast to the effect on softwoods in CTMP processes. In the manufacturing of bulky sheets, hardwood raw materials with thick walls are preferable and should be used before thin-walled hardwoods (Jackson et al. 1984). The shorter fibre length of birch fibres is compensated for by the high fibre stiffness. Obviously, high fibre stiffness is more important than a high fibre length in the manufacturing of bulky paper sheet structures.

In papermaking, sheet strength can be improved by either enhanced beating or by the addition of chemical additives. The mixing of fibres with different characteristics can be a means of creating a strong final paper product in combination with other desirable properties. One example is in the production of paperboard, when intensely beaten kraft long fibres are used to achieve a high strength and this is mixed with HTCTMP, which increases the bulk of the sheet.

To improve the molecular adhesion in the fibre/fibre contact zone, it is common to add strength additives (Lindström et al. 2005). Numerous studies have demonstrated the paper strength-enhancing effect of cationic starch (Moeller 1996, Howard, Jowsey 1989, Wågberg, Björklund 1993, Wågberg, Kolar 1996,), when adsorbed to the negatively charged fibres. It has been suggested that starch increases the specific joint strength (Howard, Jowsey 1989), molecular contact area and the number of efficient fiber-fiber joints (Moeller 1996). In mechanical or chemimechanical pulp furnishes, difficulties may exist in adsorbing high amounts of starch in a cost efficient manner due to the high amount of fines (Rundlöf et al. 2000) but, both in-plane and out-of-plane properties are considerably improved (Eriksson et al. 2005, Pettersson et al. 2006b).

All measures that are taken in order to improve the fibre flexibility of the fibre wall usually result in an improved strength but at the expense of a reduced sheet bulk in papermaking. This is true for mechanical, thermal as well as chemical treatments. On the other hand, it is possible to improve sheet strength without or with only a slight reduction of bulk at adsorption of strength improving agents onto the fibre surfaces, while protecting the inner fibre wall layers from being affected. It has been shown that polyelectrolyte multilayering technique (PEM) (Decher 1997), i.e. consecutive treatment cationic and anionic polyelectrolyte, will provide a significant improvement in both the tensile and Z-strengths, involving only a minor densification of the sheet (Wågberg et al. 2002, Pettersson et al. 2006a). The efficiency of the PEM technique was found to be due to both an improved molecular contact in the contact zone between the fibres and an increase in the number of efficient contact zones between the fibres (Wågberg et al. 2002). One example is that when consecutive layers of cationic starch and anionic CMC (carboxymethylcellulose) are subsequently applied onto fibre surfaces in kraft pulp/CTMP furnishes, the out-of-plane strength in the paper sheets was improved very significantly with only a marginal increase in density (Pettersson et al. 2006a). Since papers made from high freeness chemimechanical pulps often have a low in-plane and out-of-plane strength, PEM technology would be very advantageous for creating ductile fibre joints.

\section{Materials and Methods}

\section{Pulps and pulp fractions, laboratory studies}

A standard market unbleached softwood kraft pulp from the SCA Östrand mill, Sweden was used in furnishes together with different mill manufactured chemimechanical pulps.

Different softwood and hardwood chemimechanical pulps were used Table 1. These chemimechanical pulps cover a broad range of properties, namely regarding freeness, fibre distributions, mean fibre length and different conditions (including refining energy input) in the manufacturing process, Fig 1.

The unbleached softwood kraft pulp was circulation refined at $4 \%$ consistency in a Voith Sulzer LR1 laboratory refiner with conical refiner fillings. Fibres were beaten to 25 and $75^{\circ} \mathrm{SR}$, respectively. The unbeaten kraft pulp had a fibre length of $2.2 \mathrm{~mm}$.

Before fibre preparation, the CTMP pulps were hot disintegrated according to SCAN M10:77 and the unbleached softwood kraft pulp were reslushed according to SCAN C: 1865. After reslushing, the CTMP and unbleached softwood kraft pulp fibres were blended at a mixing ratio of $85 / 15$ or $70 / 30$, respectively.

Before mixing kraft pulp and CTMP, the CTMP was treated with either polyelectrolyte in different stages or in one single stage. When different stages (i.e. according to the PEM concept) were used, cationic starch was first adsorbed, followed by a treatment with CMC and finally with a new addition of cationic starch. The chemicals were adsorbed for $2 \mathrm{~min}$ in each layer. When only one

Table 1 - Summary of various pulps

\begin{tabular}{cccc}
\hline Pulps & $\begin{array}{c}\text { CSF } \\
(\mathbf{m l})\end{array}$ & $\begin{array}{c}\text { Refining } \\
\text { Energy }(\mathbf{k W h} / \mathrm{t})\end{array}$ & $\begin{array}{c}\text { Fibre } \\
\text { length(mm) }\end{array}$ \\
\hline HT CTMP Birch & 695 & $\sim 750$ & 0,85 \\
HT CTMP Spruce & 730 & $\sim 700$ & 1,80 \\
HT CTMP Spruce & 514 & $\sim 800$ & 1,30 \\
CTMP Spruce & 567 & $\sim 650$ & 1,00 \\
CTMP Spruce & 530 & $\sim 1100$ & 1,30 \\
\hline
\end{tabular}

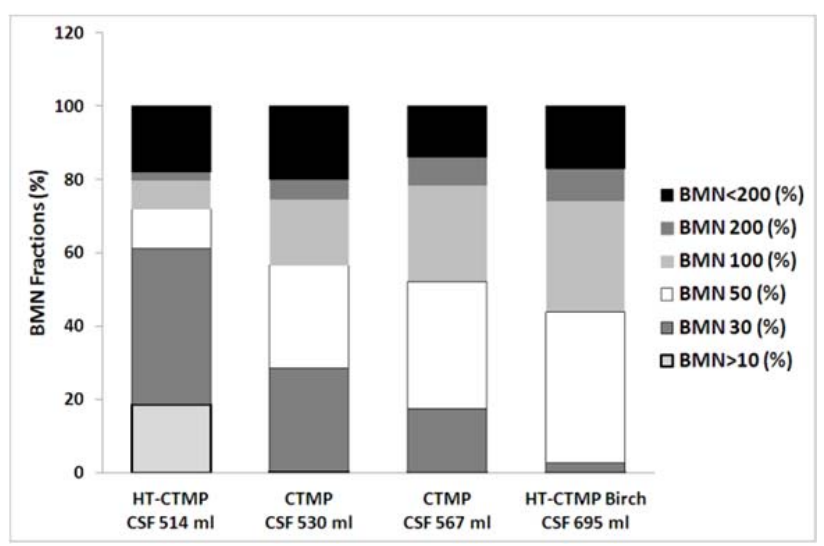

Fig 1 - BMN fractions for HTCTMP and CTMP pulps 
stage was used (i.e. according to the MIX concept) the polyelectrolytes, i.e. cationic starch and CMC, were premixed in a turbo mixer for $30 \mathrm{~s}$ before the CTMP was treated. The pre-mix was allowed to adsorb for $2 \mathrm{~min}$. After multilayer or MIX treatment, the CTMP was blended with the untreated kraft pulp and transferred to the sheet preparation equipment.

\section{CTMP and HT CTMP manufacturing for EuroFEX trial}

For the trial at the EuroFEX pilot paper machine at Innventia, Sweden, a special low energy HT-CTMP from spruce $(600 \mathrm{kWh} / \mathrm{ton}$ in refining stages, i.e. including reject refining) at CSF $744 \mathrm{ml}$ was manufactured in a mill trial performed at the SCA Östrand CTMP mill in Timrå, Sweden. In that mill the impregnation vessel is situated inside the preheater and the chips are atmospherically steamed before impregnation with $15-20 \mathrm{~kg} \mathrm{Na}_{2} \mathrm{SO}_{3}$ at $\mathrm{pH}$ 10. Turbine segments were used in the main refiner. The pulp was flash dried before transportation to Innventia for the pilot trial. As a reference, a standard mill manufactured CTMP of paperboard quality from spruce (1000 kWh/ton in the refining stages) was used.

\section{Chemicals}

Cationic starch from Lyckeby Starch, Sweden, and a CMC from CP Kelco, Finland were supplied for use in the PEM or MIX treatment. The starch was Pearl Bond 930 with a cationic degree of substitution of 0.04 and the CMC, carboxymetyl cellulose, was a Finnfix 30.

Other chemicals used (C-PAM, Bentonit) were of standard quality. The amount of each chemical added in the laboratory trial is shown in Table 2.

In the pilot trial on EuroFEX, the following chemical additives were used: Starch AMYLOFAX ${ }^{\mathrm{TM}}$ HS from Avebe, CMC FinnFix 30 from CP Kelco, retention polymer Fennopol K 7426 R from Kemira, micro particle Opazil ADV from Clariant and sizing chemical Fennosize KD 574MP from Kemira.

The starch solution was prepared by jet-cooking at $120^{\circ} \mathrm{C}$. The amount of each chemical added is shown in the trial plane in Table 3.

\section{Sheet preparation in laboratory and pilot plant trials}

Sheets in the laboratory study were made on a Formette Dynamic Sheet Former from Fibertech AB, Sweden. To simulate the conditions on a board paper machines, sheets with a grammage of $150 \mathrm{~g} / \mathrm{m}^{2}$ were formed by pumping the stock with a pulp consistency of $3 g / l,(\mathrm{pH} 7-8)$ from the mixing chest, through a traversing nozzle, into the rotating drum onto the water film on top of the wire, draining the stock to form a sheet, then pressing and drying the sheet. The paper sheets were pressed at 2.5 bars in a roll press and, thereafter, restrained dried in a plane drier at $90^{\circ}$ for $15 \mathrm{~min}$. In the pilot study, paper was produced on the research paper machine EuroFEX at Innventia, Stockholm, Sweden, equipped with two short circulations and a closed white water system (Roding, Norman 1986). Paper with a grammage of $80 \mathrm{~g} / \mathrm{m}^{2}$ was produced on the roll former unit at a lip opening of $13 \mathrm{~mm}$ at a machine speed of $500 \mathrm{~m} / \mathrm{min}$ and a forming consistency of $0.65 \%$. The lower grammage has been selected out of practical reasons. Similar conditions were
Table 2 - Chemicals added in PEM/MIX treatment in laboratory trials

\begin{tabular}{lcccc}
\hline $\begin{array}{l}\text { Chemicals } \\
\text { Layers }\end{array}$ & $\begin{array}{c}\text { First } \\
\text { layer }\end{array}$ & $\begin{array}{c}\text { PEM } \\
\text { Second } \\
\text { layer }\end{array}$ & $\begin{array}{c}\text { Third } \\
\text { layer }\end{array}$ & MIX \\
\hline Starch (kg/ton) & 20 & & 20 & 40 \\
CMC (kg/ton) & & 2 & & 2 \\
Bentonit (kg/ton) & & & 1.50 & 1.50 \\
C-PAM (kg/ton) & & & 0.50 & 0.50 \\
\hline
\end{tabular}

Table 3 - Trial plane for the EuroFEX at Innventia in Stockholm

\begin{tabular}{lcccccc}
\hline Trialpoints & $\begin{array}{c}\mathbf{1} \\
\text { REF }\end{array}$ & $\begin{array}{c}\mathbf{2} \\
\text { REF }\end{array}$ & $\begin{array}{c}\mathbf{3} \\
\text { REF }\end{array}$ & $\begin{array}{c}\mathbf{4} \\
\text { PEM }\end{array}$ & $\begin{array}{c}\mathbf{5} \\
\text { PEM }\end{array}$ & $\begin{array}{c}\mathbf{6} \\
\text { MIX }\end{array}$ \\
\hline $\begin{array}{l}\text { CTMP, } 1000 \\
\text { kWh/t }\end{array}$ & $80 \%$ & $80 \%$ & & & & \\
HT CTMP, 600 & & & & & & \\
kWh/t & & & $80 \%$ & $80 \%$ & $80 \%$ & $80 \%$ \\
SW 25 SR & $20 \%$ & $20 \%$ & $20 \%$ & $20 \%$ & $20 \%$ & $20 \%$ \\
CTMP Post ref & 0 & 200 & & & & \\
kWh/t & & & & & & \\
Starch (kg/ton) & 12.8 & 12.8 & 12.8 & 38 & 63 & 63 \\
CMC (kg/ton) & & & & 3.7 & 6.2 & 6.2 \\
AKD (kg/ton) & 4.5 & 4.5 & 4.5 & 4.5 & 4.5 & 4.5 \\
Bentonit (kg/ton) & 2 & 2 & 2 & 2 & 2 & 2 \\
C-PAM (kg/ton) & 0.5 & 0.5 & 0.5 & 0.5 & 0.5 & 0.5 \\
NaHCO3 (mg/l) & 200 & 200 & 200 & 200 & 200 & 200 \\
\hline
\end{tabular}

used in all the trials. The press section of the EuroFEX consists of one double felted roll press followed by two SymBelt presses (Rigdahl et al. 2000). The rolls in the two shoe presses are inverted in relation to each other. The linear load in the first press was $20 \mathrm{kN} / \mathrm{m}$ and the linear loads in the second and third presses were between 500 and $700 \mathrm{kN} / \mathrm{m}$. The papers were dried in an off-line single dryer under tension in both MD and CD.

\section{Sheet testing}

Tensile testing was conducted according to SCAN P: 67 and grammage, thickness and density were evaluated according to SCAN C 28:76; Z-strength testing was conducted according to SCAN-P 80:98. Scott Bond testing was conducted according to Tappi 833 pm 94.

\section{Results}

\section{Reinforcement of CTMP with beaten kraft pulp, laboratory studies}

Sheets were prepared in the Formette Dynamic from five CTMP or HTCTMP pulps which were blended with 15 or $30 \%$ kraft pulp, respectively. Two different degrees of beating of the kraft pulp were tested, i.e. $25^{\circ} \mathrm{SR}$ and $75^{\circ} \mathrm{SR} .25^{\circ} \mathrm{SR}$ represent a conventionally used degree of beating for a reinforcement pulp, whereas $75^{\circ} \mathrm{SR}$ is an extremely tough treatment. The best reinforcement effect was achieved with the most intensely beaten kraft fibres, Fig 2-5. These fibres are certainly also thus that proved to be the most flexible. The reinforcement effect is marked only for the reference pulp in Fig 2-5, but the effects followed a similar pattern for all the tested CTMP pulps. 
The increase in strength properties is a result of the densification of the sheet structure, Fig 2-5. There is a very good correlation between Z-strength and density for all the tested furnishes in spite of the remarkably high differences in the fibre length distribution (Table 1) and in the fibre raw materials (i.e. spruce and birch) in the tested CTMP, Fig 2. The Scott-Bond develops in a similar manner as that for the Z-strength, Fig 3. Tensile index and strain at break increase almost linearly with density regarding the addition of kraft pulps Fig 4-5. The best outcome at a certain density is achieved from furnishes based on spruce HTCTMP with highest CSF value. It is obvious that the addition of $15-30 \%$ of kraft pulp to a CTMP furnish, independent of the degree of fibre flexibility of the kraft pulp fibres, results in both tensile and out-of -plane strength improvements that are closely related to densification.

However, in the middle plies in paper board composites, it is advantageous to be able to increase the Z-strength with as small a simultaneous increase in sheet density as possible. How the strength properties can be improved with a maintained density is discussed in the following section.

\section{PEM and MIX treatments on CTMP, laboratory studies}

Sheets were prepared in the Formette Dynamic with the same CTMP/HTCTMP fibres as in the kraft reinforcement study (Fig 2-5). Fibres were surface treated either with multilayer technique using cationic starch/CMC/cationic starch addition or by a pre-MIX

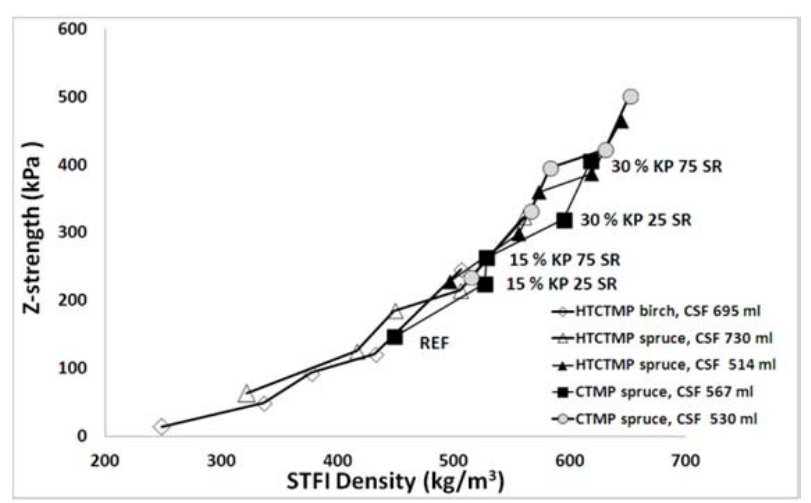

Fig 2 - Z-strength vs. density of different CTMP and HTCTMP combined with kraft pulp in 15 and 30\% ratios. The different additions of kraft pulp are marked only for the reference pulp, but the effects are similar for all pulps in Fig 2-5.

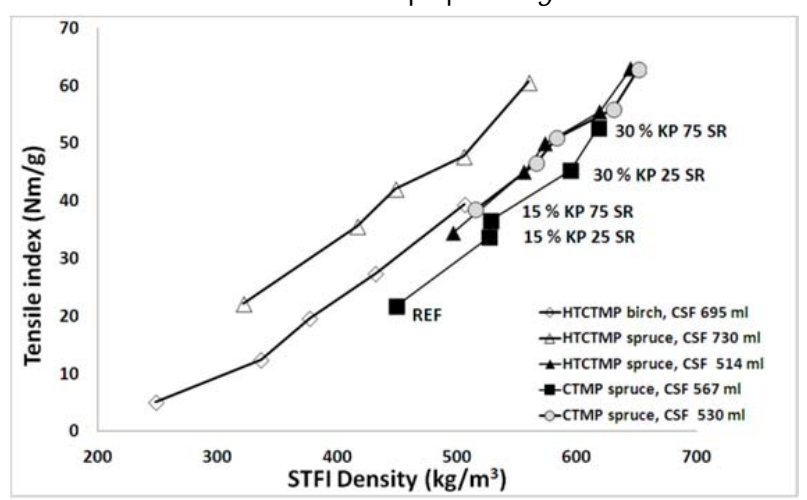

Fig 4 - Tensile index vs. density of different CTMP and HTCTMP combined with kraft pulp in 15 and 30\% ratio. technique with the same amount of chemicals added in one single treatment. Strength data for the sheets made from these pulps and pulps furnishes reinforced with 15\% kraft pulps beaten to $25^{\circ} \mathrm{SR}$ are contained in Fig 6-9. The figures show that it is possible to double both the Zstrength, Scott Bond, tensile index and stretch at break with PEM or pre-MIX treatment of CTMP/HTCTMP at a certain sheet density, i.e. far beyond the limits that can be achieved with reinforcement, using only kraft pulp. The results clearly show that it is possible to produce bulky paper structures on a totally new level of in-plane and out-of-plane properties from CTMP and HTCTMP that have been treated with PEM or pre-MIX and reinforced with kraft pulp. These promising laboratory results provided the courage to invest in a pilot trial at EuroFEX, which is discussed in the next section. This was done to be able to confirm the findings from the laboratory study at conditions that are close to those on paperboard machines in industrial scale.

\section{Pilot plant trial on EuroFEX}

The results from the pilot plant study at Innventia EuroFEX paper machine are summarized in Fig 10-14. As shown in Fig 12, there was a significant increase in the tensile index with both additions of the three multilayers (PEM) and pre-mixed (MIX) treatments, in addition to a minor increase in sheet density. The effect of the three layers of starch-CMC-starch is at almost the exact same spot as for the pre-mixed value, so it can be stated that both techniques can be used and will provide

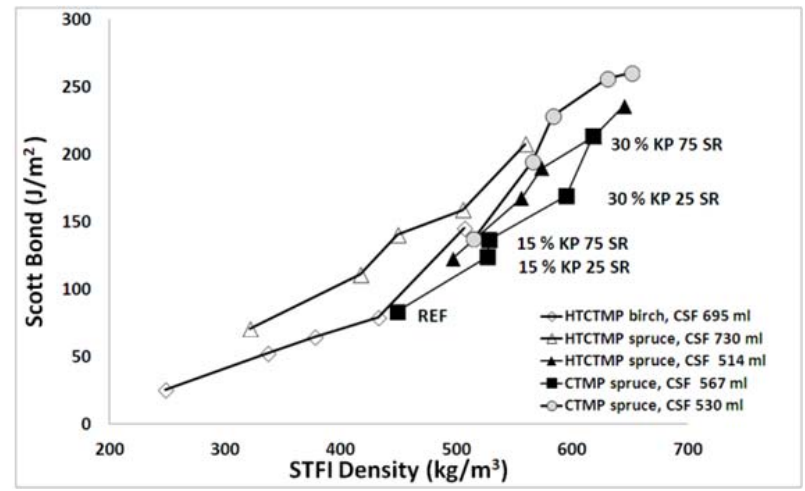

Fig 3 - Scott Bond vs. density of different CTMP and HTCTMP combined with kraft pulp in 15 and $30 \%$ ratio.

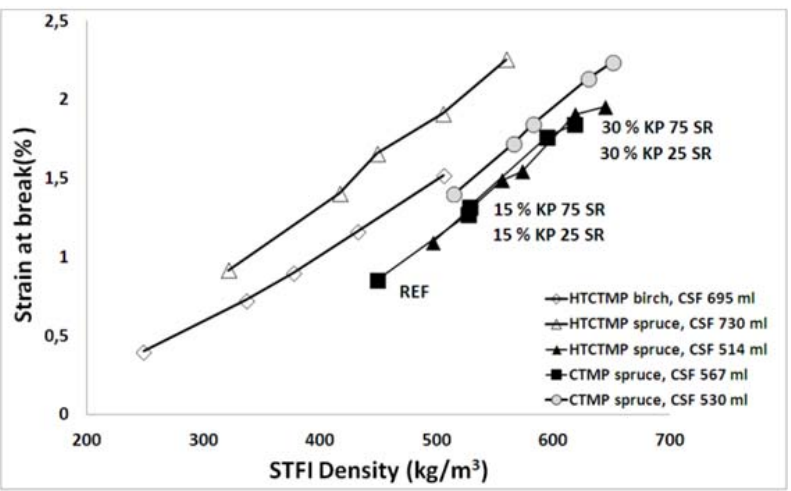

Fig 5 - Strain at break vs. density of different CTMP and HTCTMP combined with kraft pulp in 15 and $30 \%$ ratio. 


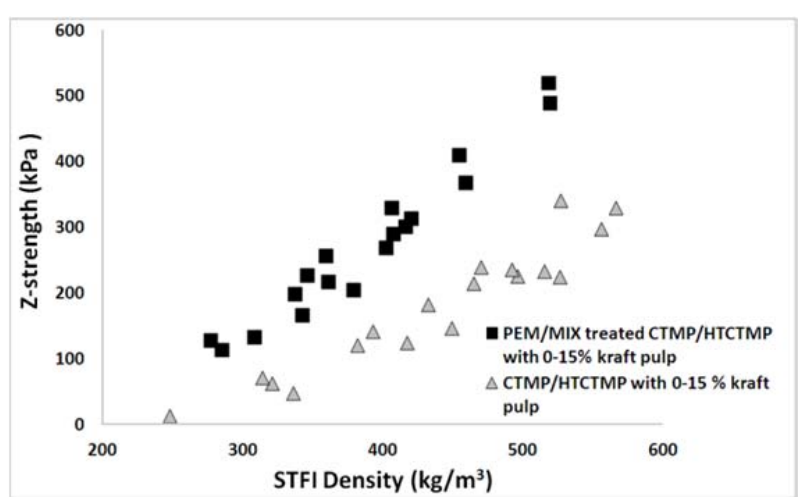

Fig 6 - Z-strength vs. density of different CTMP and HTCTMP with and without PEM/MIX treatments, reinforced with kraft pulp $\left(25^{\circ} \mathrm{SR}\right)$ in $0-15 \%$ ratios.

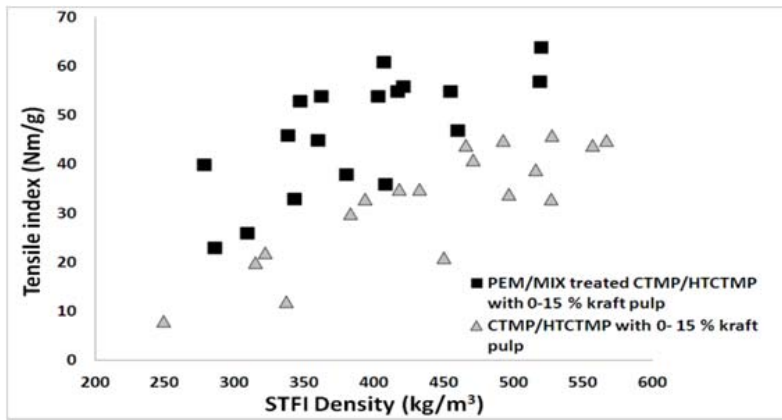

Fig 8 - Tensile index vs. density of different CTMP and HTCTMP, with and without PEM/MIX treatments, combined with kraft pulp $25^{\circ} \mathrm{SR}$ in $0-15 \%$ ratios.

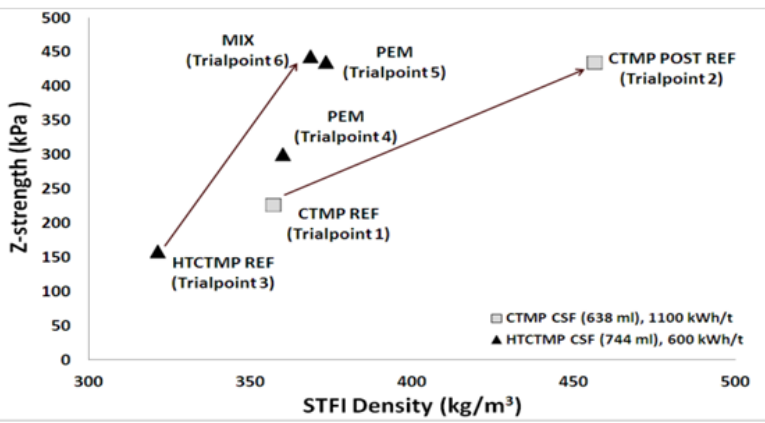

Fig 10 - Z-strength vs. density of HTCTMP, with and without PEM/MIX treatments, reinforced with $20 \%$ kraft pulp compared with post refined CTMP.

the same result as long as the amount of chemicals is the same. The LC post refined CTMP increased the tensile index to almost the same value as for the PEM/MIX treatment at additional energy consumption of about $200 \mathrm{kWh} / \mathrm{ton}$, but with an increase in sheet density. The low consistency post refining appears to affect the tensile index in a similar manner to that for the addition of kraft pulp. The density is about $20 \%$ lower at the same tensile index in favour of the surface treated HTCTMP furnish with the high dosage of polymers (trial points 5,6 in Table 3) and about 15\% lower at the low dosage (trial point 4 in Table 3). This confirm the positive effects that was find in the laboratory trial (compare results in Fig 8 and 12)

Out-of-plane strength is plotted versus density in Fig 10 and 12. The sheets made from the HTCTMP treated with 3 layers of starch-CMC-starch or according to the MIX concept had the same Z-strength as the post refined

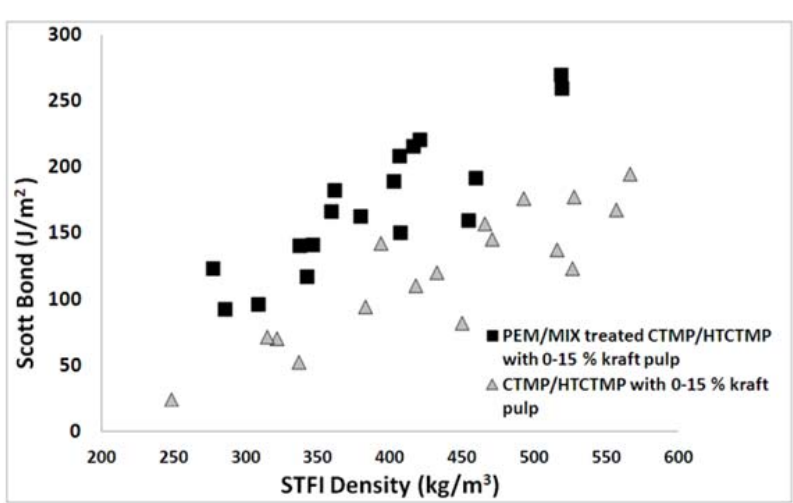

Fig 7 - Scott Bond vs. density of different CTMP and HTCTMP, with and without PEM/MIX treatments, reinforced with kraft pulp $\left(25^{\circ} \mathrm{SR}\right)$ in $0-15 \%$ ratios.

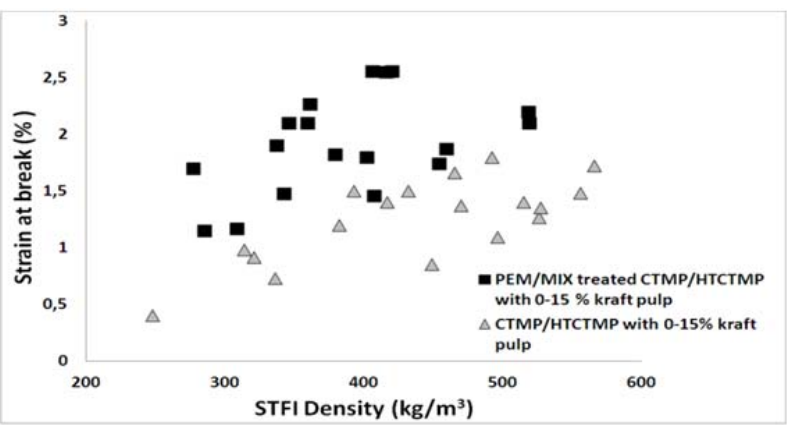

Fig 9 - Stretch at break vs. density of different CTMP and HTCTMP, with and without PEM/MIX treatments, reinforced with kraft pulp $25^{\circ} \mathrm{SR}$ in $0-15 \%$ ratios.

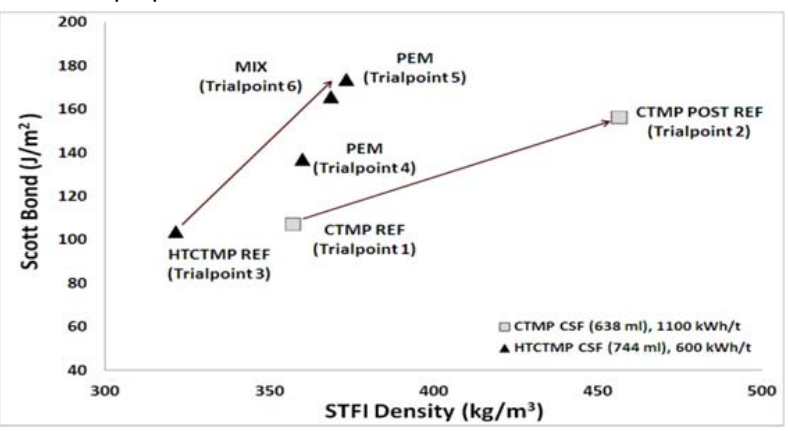

Fig 11 - Scott Bond vs. density of HTCTMP, with and without PEM/MIX treatments, reinforced with $20 \%$ kraft pulp compared with post refined CTMP.

reference CTMP but, at a much lower density (approximately $20 \%$ at the high dosage of polymers).The refining energy required for the manufacturing of the HTCTMP was only about $600 \mathrm{~kW} / \mathrm{h}$ as compared to about $1100 \mathrm{~kW} / \mathrm{h}$ at the high consistency refining of the reference CTMP (standard board quality). The reference pulp was also post refining during the low consistency stage with an energy input of $200 \mathrm{kWh} /$ ton in order to achieve the same Z-strength as that for the treated HTCTMP. The energy reduction was thus about $50 \%$ in this particular example, in order to achieve the same outof strength value. The surface modification of HTCTMP has an even better effect on strain at break than on the strength properties.

Adsorption isotherms were used to determine the amount of starch/CMC adsorbed in each layer (Pettersson et al 2006a). That ratio between the chemicals from the isotherms was also used for the pre-mixed technique. The 


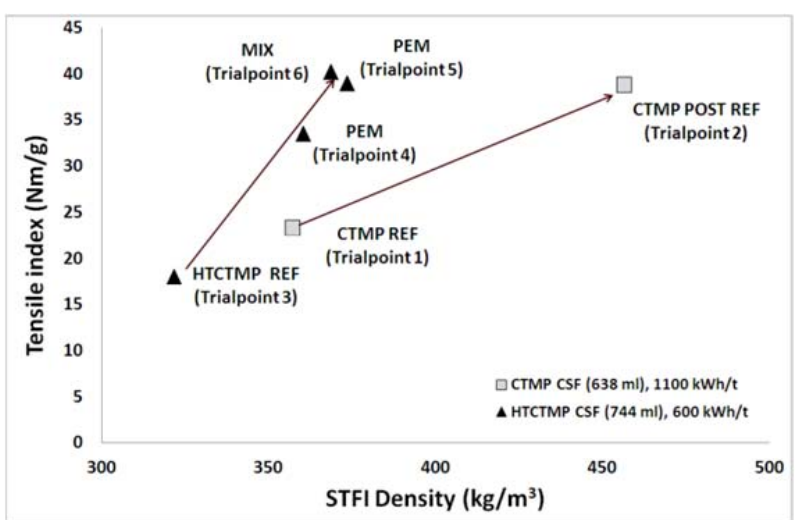

Fig 12 - Tensile index vs. density of HTCTMP, with and without PEM/MIX treatments, reinforced with $20 \%$ kraft pulp compared with post refined CTMP

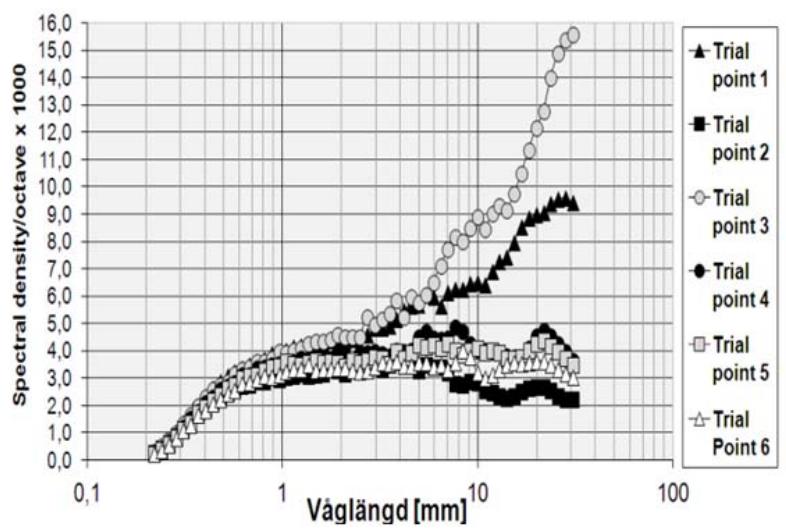

Fig 14 - Formation data on the different trial points (see Table 3) on the EuroFEX trial.

strength/bulk results for both techniques are equal as long as the same amount of chemicals is used, which indicate that we might have got a layered polymers microstructure even when the Mix technology was used.

Both the multilayer technique and the pre-mixed technique positively affected the strength properties of the produced paper at a minor change in density. The exact explanation regarding how the pre-mixed treatment, as compared to the more established multilayer technique, affects the strength properties is not yet known, but the results clearly indicate that it is possible to produce high quality paper board sheet structures with a new more simple technique, i.e. pre-mixed treatment on a low energy HTCTMP with large amounts of long and stiff fibres.

It is well known that average fiber length but also dewatering has a significant impact on the resulting sheet formation. The improvement of the formation is related to both refining and addition of strength chemicals. It is clearly visible in Fig 14 that post refining of the spruce reference pulp had a huge impact on formation mainly related to the average fiber length reduction. Average fiber length went from $1,76 \mathrm{~mm}$, CSF $638 \mathrm{ml}$ down to $1,3 \mathrm{~mm}$ and CSF $369 \mathrm{ml}$ after post refining. Also the expected change in dewatering characteristics might have had an impact. The HT CTMP with long and stiff fibers and high freeness, CSF $744 \mathrm{ml}$, makes it easy to dewater and this deteriorated the formation shown in trial point 3. (Hallgren, Lindström 1988). It is known that dissolved polymer (anionic or non-ionic) or overdosing of cationic

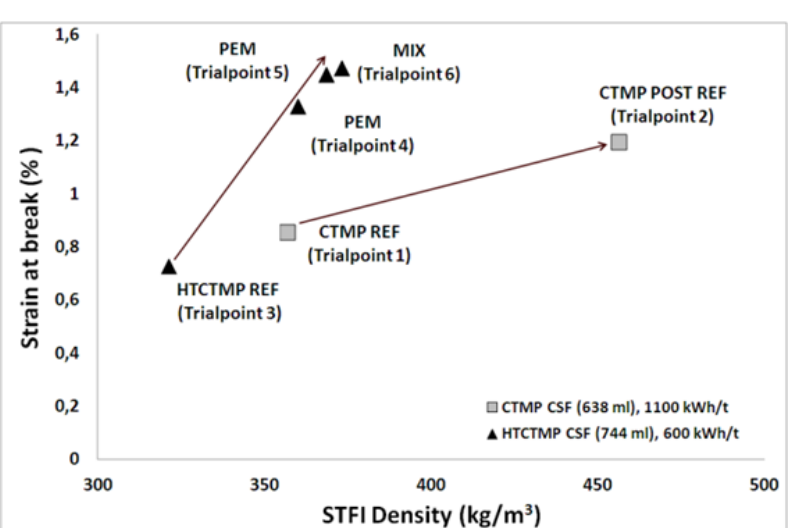

Fig 13 - Stretch at break vs. density of HTCTMP, with and without PEM/MIX treatments, reinforced with 20\% kraft pulp compared with post refined with CTMP.

polymers circulation in the white water have a significant effect on improving formation due to increased shear viscosity during dewatering. In trial point 4-6 a significant amount of cationic starch and anionic CMC was dosed to the system resulting in decreased dewatering and improved formation (Lee, Lindström 1989).

\section{Discussion}

In this paper it is shown how both in-plane and out-ofplane sheet properties are improved at surface modification of CTMP fibres with a combination of cationic/anionic polymers. The improved strength is achieved at just a minor densification of the sheet structure. This is particularly of interest in design of folding boxboards, where a bulky middle layer in its multilayer structure is a key component to be able to form a stiff and light product. The strength improvements make it possible to use stiff CTMP fibres to create very bulky sheet structures with a sufficiently high strength profile. Such CTMP fibres are most favorably manufactured at as low energy input in the refining stage as possible, as long as the shive content is low enough. To get an optimum layered product the cost of added polymers to achieve a given strength improvement had to be compare to the reduced energy consumption in manufacturing of CTMP and the opportunity to reduce sheet grammage due to an improved bulk, i.e. design of a both stiff and light product. Such optimization has to be done in consideration of product specifications for folding boxboards in different applications.

\section{Conclusions}

The main goal of this study was to determine costefficient furnishes for a centre ply of a multi-ply paperboard, i.e. folding boxboard, when CTMP is added. The most interesting findings are that;

- Strong and bulky paperboard plies can be manufactured from HTCTMP after surface treatments with starch/CMC. Energy consumption in the refining of such HTCTMP, including reject refining, can be reduced to about $600 \mathrm{kWh} / \mathrm{ton}$

- The in-plane strength (tensile index), out-of-plane strength (Z-strength, Scott-Bond) and strain at break of a CTMP based sheet can be doubled at a 
maintained sheet bulk (density) after surface treatments of the fibres with starch/CMC

- Surface treatment with starch/CMC can be performed alternatively with a PEM (polyelectrolyte multilayer) or MIX concept, which both provided the same effect

- In forming a bulky sheet structure from CTMP fibres, the fibre length appears to be less important than the fibre wall stiffness

- With the addition of a kraft pulp, independent of the degree of beating, or low consistency post refining of the CTMP, the sheet strength can be improved only at the expense of a reduced bulk

\section{Acknowledgements}

We would like express our thanks to the staff at Stora Enso R\&D, Karlstad and SCA R\&D, Sundsvall for their excellent assistance with the laboratory work. SCA Östrand Timrå for their great assistance during the mill trials and Innventia, Stockholm for their incredible job during the pilot trial at EuroFEX. The Knowledge Foundation is gratefully acknowledged for the financial support for this three year project "Low energy CTMP for paperboard"

\section{Literature}

Bengtsson, G. (2005): CTMP in production of high quality packaging board, Proceedings from International Mechanical Pulping Conference, Oslo, 7-13.

Decher, G. (1997): Fuzzy nanoassemblies: Toward layered polymeric multicomposities, Science, 277, 1232.

Eriksson, M., Pettersson, G. and Wågberg, L. (2005): Application of polymeric multilayers of starch onto wood fibres to enhance strength properties of paper, Nord Pulp Paper Res. J.15 (4), 256-265.

Fellers, C., De Ruvo, A., Htun, M., Carlsson, L., Engman, M and Lundberg, R. (1983): Carton Board - Profitable use of pulp and processes, STFI, Stockholm.

Fineman, I. (1985): Let the paper product guide the choice of mechanical pulp, Proceedings from International Mechanical Pulping Conference, Stockholm, 203-214.

Granfeldt, T., Falk, B., Denton, B., and Åkerlund, G. (2001): Aspen CTMP-where are we now and where is it heading? Proceedings from International Mechanical Pulping Conference, Helsinki 2, 315-327.

Hallgren, H. and Lindström, T. (1988): The influence of stock preparation on paper forming efficiency on a paper machine, XXIII, Eucepa Conference, Harrogate, Vol, 35-49.

Howard, R.C. and Jowsey, C. (1989): The effect of cationic starch on the tensile strength of paper, J. Pulp Paper Sci. 15, 225-228.

Höglund, H. (2002): Mechanical pulp fibers for new and improved paper grades, Proceedings from $7^{\text {th }}$ International Conference on new available technology, Stockholm, 158-163.

Höglund, H. and Wilhelmsson, K. (1992): The product must determine the choice of wood type in mechanical pulping, Proceedings from International Mechanical Pulping Conference, Oslo, 1-22.

Höglund, H., Bäck, R., Danielsson, O. and Falk, B. (1994): A method of producing mechanical and chemimechanical pulp, (PCT/WO 94/16139).
Jackson, M., Åkerlund, G. and Höglund, H. (1984): Chemimechanical pulp from aspen shows promise for several grades, Pulp and Paper 58(9), 230-232.

Laamanen, M. and Lahti, J. (2008): Fibre-based packaging materials, in Book12 (Paper and Paperboard Converting) of Papermaking Science and Technology, ed. Kuusipalo,J., ISBN 978-952-5216-28-8, 212

Lee, P. and Lindström, T. (1989): Effects of high molecular mass anionic polymers on paper sheet formation, Nord Pulp Paper Res. J.4 (2), 61-70.

Lindström, T., Wågberg, L. and Larsson, T. (2005): On the nature of joint strength in paper - A review of dry and wet strength resins used in paper manufacturing, Advances in Paper Science and Technology, S.J, I' Anson (Ed), The Pulp and Paper Fundamental Res. Soc., UK. 457.

Moeller, H. (1996): Cationic starch as wet end strength additive, Tappi, 59 (12), 211-214.

Moldenius, S. and Jackson, M. (1989): New Trends in Mechanical Pulping for Printing and Writing, Newsprint and Light Weight Coating Grades. Second Generation Chemimechanical Pulp, Appita 42 (4), 291.

Pettersson, G., Wågberg, L. and Höglund, H. (2006a): The use of polyelectrolyte multilayers of cationic starch and $\mathrm{CMC}$ to enhance strength properties of paper from mixtures of unbleached chemical pulp and CTMP: Part II, Nord Pulp Paper Res. J.21 (1), 115-121.

Pettersson, G., Wågberg, L. and Höglund, H. (2006b): The use of polyelectrolyte multilayers of cationic starch and CMC to enhance strength properties of paper from mixtures of unbleached chemical pulp and CTMP: Part II. Nord Pulp Paper Res. J.21 (1),122-128.

Rigdahl, M., Bäckström, M., Hedström, C-G., Norman, B., Kilian, M. and Talja, R. (2000): Impulse technology on the EuroFEX machine, Tappi J. 68(5), 11.

Roding, S. and Norman, B. (1986): FEX, the new STFI experimental paper machine, Tappi J. 68(5), 94.

Rundlöf, M., Sjölund, A., Ström A, and Wågberg, L. (2000): The effect of dissolved and colloidal substances from TMP on the properties of TMP fines, Nord Pulp Paper Res. J.21 (12), 423.

Thomas, H. (1997): Mechanical pulp in paperboard packaging, Proceedings from International Mechanical Pulping Conference, Stockholm, 9-15.

Westerlind, E-L and Höglund, H. (2006): Chemimechanical pulp made from birch at higher temperature, Nord Pulp Paper Res. J.21 (2), 217-221.

Wågberg, L and Kolar, K. (1996): Adsorption of cationic starch on cellulosic fibres, Tappi, 59 (12), 121.

Wågberg, L and Björklund, M. (1993): Adsorption of cationic potato starch on cellulosic fibres, Nord Pulp Paper Res. J.8 (4), 399.

Wågberg, L., Forsberg, S., Johansson, A and Juuntti, P. (2002): Engineering of fibre surface properties by application of the polyelectrolyte multilayer concept, Part I: Modification of paper strength, J. Pulp Paper Sci. 28 (7), 222.

Manuscript received November 11, 2014 Accepted February 16, 2014 